\title{
DIÁLOGO E ENSINO-APRENDIZAGEM NA FORMAÇÃO TÉCNICA EM SAÚDE
}

\author{
DIALOGUE AND TEACHING-LEARNING IN TECHNICAL TRAINING IN HEALTH
}

\begin{abstract}
Silvana Lima Vieira ${ }^{1}$ iD (0000-0002-9663-3691), Gilberto Tadeu Reis da Silva ${ }^{2}$ iD (0000-0002-0595-0780), Rosana Maria de Oliveira Silva ${ }^{2}$ iD (0000-0003-3371-6550), Simone Coelho Amestoy ${ }^{3}$ (iD) (0000-0001-8310-2157)
\end{abstract}

\author{
${ }^{1}$ Universidade do Estado da Bahia - Campus I, Departamento de Ciências da Vida, Salvador, Bahia, \\ Brasil. <silvana.limavieira@gmail.com> \\ ${ }^{2}$ Universidade Federal da Bahia, Escola de Enfermagem, Salvador, Bahia, Brasil. \\ ${ }^{3}$ Universidade Federal do Vale do São Francisco, Petrolina, Pernambuco, Brasil.
}

Resumo O objetivo foi analisar o diálogo no agir-aprendente do educando e no agir-educativo das educadoras no movimento ensino-aprendizagem em um curso técnico de nível médio em enfermagem promovido pela Escola de Formação Técnica em Saúde do Sistema Único de Saúde, para comunidade em contexto de vulnerabilidade social. Estudo qualitativo, do tipo estudo de caso, ancorado no referencial de Paulo Freire. Participaram doze educandos e cinco educadoras, com os dados coletados entre dezembro de 2014 e setembro de 2015 por meio de entrevista semiestruturada, observações registradas em diário de campo e análise documental. O diálogo no uso de metodologias inovadoras e problematizadoras proporcionou a construção e estreitamento de vínculos, contextualização do conteúdo teórico com base no território e na leitura de mundo dos educandos em busca de uma relação dialógica. O potencial formativo embasado no pensamento freireano orientou a reflexão e prática fundamentada no diálogo que contribuiu para o processo educativo emancipatório e plural. Concluímos que o diálogo proporcionou uma relação de proximidade entre educadores e educandos, revelando-se como ideia/força, favorecendo a dinâmica sensível e crítica que permeou e constituiu o movimento ensino-aprendizagem para educandos em contexto de vulnerabilidade social.

Palavras-chave movimento ensino-aprendizagem; educação profissionalizante; enfermagem; diálogo; vulnerabilidade social.
Abstract This article aimed to analyze the learner's acting-learning and the educating-acting of the educators in the teaching-learning movement in an Intermediate Level Technical Course in Nursing promoted by the School of Technical Formation in Health of Brazilian Unified Healht System. The methodology had a qualitative, exploratory, case study approach, anchored in Paulo Freire's framework. Twelve students and five teachers participated in this study, with data collected from December 2014 to September 2015 through semi-structured interviews, observations recorded in a field diary and document analysis. The use of innovative and problematizing methodologies showed that the dialogue provided the construction and strengthening of bonds, contextualization of the theoretical content based on the territory and the students' reading of the world in search of a dialogical relation. The formative potential of Freire's thinking guided reflection on practice in dialogues, with a view to constituting emancipatory educational processes. We conclude that the dialogue provided a close relationship between educators and learners, revealing itself as an idea/force, favoring the sensitive and critical dynamics that permeated and constituted the teaching-learning movement for students in a context of social vulnerability.

Keywords teaching-learning movement; vocational education; nursing; dialogue; social vulnerability. 


\section{Introdução}

A aproximação com a temática da formação e educação profissional decorreu da percepção como sujeito do movimento ensino-aprendizagem nos variados contextos e trajetórias da vida pessoal, acadêmica e profissional. A perspectiva teórica ancorada em Paulo Freire veio ao encontro desse estudo ao ampliar o olhar sobre educandos em contextos de vulnerabilidade social e o diálogo como possibilidade de superar as situações-limites. Vislumbramos, com base em leituras sobre o ensino e a aprendizagem por meio do diálogo, um processo de interação crítico e emancipador de modo a divulgar e estimular ações transformadoras para homens/mulheres/cidadãos, como seres em busca do próprio 'ser-mais' na recondução de seus projetos de vida, da margem para o centro das suas vidas em sociedade (Freire, 2013a).

O presente estudo enfocou o movimento ensino-aprendizagem no curso de habilitação profissional de técnico em enfermagem para educandos(as) em contexto de vulnerabilidade social, promovido por uma Escola de Formação Técnica em Saúde do Sistema Único de Saúde (EFTS-SUS). O movimento ensino-aprendizagem é ato e processo político de (trans)formação, isento de neutralidade, constituído pela triangulação do agir aprendente do educando, da ação educativa do educador e do conteúdo programático, em determinado espaço-tempo pedagógico (Freire, 2001, 2014a). Ocorre em um movimento dialético de troca e pode, portanto, influenciar e sofrer influências, construir, destruir ou manter estruturas, transformar, colocar em forma ou (de)formar, pois é intrínseco à vida de todos os seres humanos desde o seu nascimento (Freire, 2011a, 2013a). Por estar em movimento, possui força e tensão, por vezes visíveis, noutras invisíveis ou frágeis, intencionais ou ingenuamente provocadas pelos sujeitos-agentes em ação (Dewey, 1959, 1971; Freire, 2013a; Westbrook e Teixeira, 2010; Vieira, 2017).

Nesse movimento de ensino-aprendizagem, o diálogo assume protagonismo, representado pelo encontro entre sujeitos como seres pensantes, engajados em modificar a realidade na qual estão inseridos, por meio de uma relação horizontal, empática, de troca, humildade e respeito entre educadores e educandos e coerência entre o que é dito e feito (Freire, 2005, 2011b).

Na proposta de uma educação humanista-libertadora, o diálogo apresenta-se como uma das categorias centrais de um projeto político pedagógico crítico, mais propositivo e esperançoso em relação ao futuro, com implicação entre a palavra dita e a ação humanizadora (Zitkoski, 2010).

Nessa toada, o diálogo pode ser compreendido como confirmação coletiva entre educador e educandos no ato comum de conhecer e reconhecer o objeto investigado. Em consequência, em vez de transferir o conhecimento de forma estática, por meio de uma cultura verticalizada, o diálogo requer uma 
aproximação dinâmica na direção do objeto, englobando todos os atores que compõem o processo de ensino-aprendizagem (Freire e Shor, 2011).

Portanto, o diálogo não torna os sujeitos iguais, mas sinaliza a posição democrática existente entre eles e possui significado relevante, tendo em vista que os sujeitos dialógicos, além de conservar sua identidade, a defendem, crescendo um com o outro. Assim, o diálogo não nivela, não promove reducionismos; ao contrário, fomenta o respeito entre os sujeitos engajados na transformação coletiva (Freire, 2005).

Ao considerar, ainda, o pensamento freireano sobre o diálogo, cabe mencionar que se trata de um momento em que os seres humanos se aproximam para refletir sobre sua realidade tal como a fazem e refazem, invalidando a dominação e a obscuridade, ao sustentar a liberdade dos participantes de refazer sua cultura. Nesta senda, o discurso tradicional convalida as relações sociais dominantes e a forma herdada e oficial do conhecimento, por isso a importância de transpor as barreiras existentes no ensino. Percebemos então que a educação dialógica parte do entendimento que os educandos têm de suas experiências cotidianas, emerge do concreto, do senso comum, para possibilitar o alcance de uma compreensão mais rigorosa da realidade (Freire e Shor, 2011). Para tanto, buscamos discutir o diálogo na perspectiva freireana no movimento ensino-aprendizagem em um curso técnico em enfermagem para educandos em contexto de vulnerabilidade social.

Em um conceito polissêmico e multifacetado, a vulnerabilidade social é composta por diversos indicadores como: falta de recursos materiais, cognitivos e de informação; renda e pobreza; estigmas sociais e discriminação (Ayres, França e Calazans, 2003). Pode, portanto, ser transitória, não se traduzindo como uma condição fatalista e determinante aos seres humanos.

Com base nos aspectos relacionados sobre o movimento ensino-aprendizagem, as ideias e os conceitos de Paulo Freire, vulnerabilidade social, políticas educacionais, habilitação profissional do técnico em enfermagem e a parceria EFTS-SUS com as Secretarias de Segurança Pública (SSP) e de Saúde do Estado da Bahia (SESAB), surgiram indagações considerando a especificidade desta formação ser voltada à moradores de comunidades atendidas por Base Comunitária de Segurança (BCS), implantadas em áreas com importante estatística criminal em relação ao número de habitantes e à localização estratégica de organizações criminosas.

Essa ação intersetorial foi derivada da política de redução de danos do Programa Pacto pela Vida (PPV) e constitui um caso a ser estudado, visto que a formação destina-se à moradores sem vínculo ou aproximação com o serviço de saúde ou SUS, mudando dessa forma o escopo de atuação da EFTS-SUS, que é a formação e qualificação de profissionais de saúde do SUS e para o SUS.

O programa PPV foi instituído na Bahia em 2011 e esteve diretamente ligado ao Governo juntamente com 13 secretarias de Estado, objetivando, 
principalmente, a redução de crimes violentos letais intencionais e crimes violentos contra o patrimônio. Esse programa de segurança pública ligado à cidadania relaciona atividades policiais a ações sociais e estipula atividades ditas de prevenção social voltadas para a população identificada como vulnerável, em áreas críticas em termos de criminalidade.

As ações executadas pelo conjunto das secretarias de Estado tinham como objetivo reafirmar direitos e possibilitar acesso a serviços públicos indispensáveis e muitas vezes ausentes nas referidas áreas ou unidades territoriais de implementação de planos integrados de ação das policias civil e militar - e BCS - com propósito de promover a convivência pacífica em localidades identificadas como críticas (Bahia, 2017; Brasil, 2006).

No estado da Bahia até o ano de 2015 foram instaladas 17 BCS, sendo 11 na capital e seis no interior do estado, com a proposta de aproximar a polícia dos moradores e aumentar a sensação de segurança nas áreas de risco, configurando-se como referência para a execução de ações sociais transversais em seu entorno, com objetivo de redução de índices de violência e criminalidade, promoção da segurança e convivência pacífica, melhorando a integração das instituições de segurança pública com a comunidade local (Bahia, 2017).

Nesse contexto, as BCS, por meio de parcerias institucionais, oferecem: cursos de capacitação, pré-vestibular do programa Universidade para Todos, curso de alfabetização para jovens e adultos, ações de saúde, mutirões para serviços como emissão de documentos e cadastramento no programa Bolsa Família e acesso a computadores conectados à internet para moradores do bairro, pelo Centro Digital de Cidadania. As necessidades locais são delimitadas em conjunto com a comunidade e classificadas por eixos de trabalho: assistência social, educação, cultura, formação profissional, esporte e lazer, infraestrutura e saúde.

No âmbito da educação profissional, destaca-se a iniciativa da Secretaria de Saúde do Estado da Bahia, por intermédio da EFTS-SUS, em parceria com a SSP, na oferta de cursos técnicos em enfermagem e de saúde bucal para pessoas residentes na comunidade do Complexo de Amaralina, escolhidos pela própria comunidade juntamente com líderes comunitários e religiosos locais.

Coadunando com os princípios pedagógicos da escola técnica, por uma educação libertadora, embasada nas experiências progressistas, é que consideramos ser possível a emancipação social na construção de caminhos alternativos para projetos inovadores em educação, ressignificando o tempo de possibilidades e não de determinismos, para dessa forma assumir a luta pelo inédito viável.

Assim, torna-se imprescindível a criticidade, que, para Freire (2016), é a capacidade do educando e do educador de refletirem a realidade na qual estão inseridos, possibilitando a constatação, o conhecimento e a intervenção para transformá-la. Entretanto, por vezes, o senso crítico do educando tem 
sido mitigado e não estimulado, a contento, pelo educador, fazendo necessário que educador e educando percebam-se como homens e mulheres inconclusos e inacabados, em constante processo de aprendizagem e construção ética.

Os educandos em saúde que vivem em vulnerabilidade social têm diversas amarras sociais que os tornam oprimidos e, em virtude disso, precisam ser ouvidos com atenção e valorizados, para que tomem consciência de seu estado de opressão e da busca pela autonomia. Freire (2011b) destaca que ninguém é autônomo para depois decidir; os homens vão construindo sua autonomia com base em experiências e decisões tomadas. E o ambiente de ensino é a chave para o início da transposição de adversidades vivenciadas pelos educandos.

Outro ponto que se ressalta é que a formação de profissionais de enfermagem no Brasil tem sido uma demanda social inquestionável e de significativa importância, sobretudo se considerados o cenário de construção da chamada sociedade do conhecimento e o acelerado e desordenado crescimento de cursos e oferta de vagas nas instituições de ensino (nível médio e superior) e, ainda, as mudanças que ocorrem no mundo do trabalho, com a introdução de novas tecnologias. Essa demanda foi parcialmente contemplada pelas políticas públicas de educação, reforçada no Plano Nacional da Educação para o decênio de 2014-2024, principalmente no que tange à oferta de no mínimo $25 \%$ das matrículas de educação de jovens e adultos nos ensinos fundamental e médio na forma integrada à educação profissional e na proposição de triplicar as matrículas da educação profissional técnica de nível médio, assegurando a qualidade da oferta e pelo menos $50 \%$ da expansão no segmento público (Brasil, 2014).

Por ser um movimento de ensino-aprendizagem no âmbito da educação profissional para adultos inseridos no contexto de política de redução de danos, considerou-se necessário o constante diálogo entre educadores e educandos, de forma a situá-los e midiatizá-los no mundo, com crítica e reflexão sobre a ação, considerando a leitura do mundo dos sujeitos envolvidos.

Com base no pensamento freireano da não neutralidade da educação e compreendendo-a como ato político, permeado por ideologia, propõe-se analisar o diálogo, como ideia-força freireana, no movimento ensino-aprendizagem em um curso técnico de nível médio em enfermagem promovido por uma EFTS-SUS.

\section{Caminho percorrido}

Esta investigação resultou da tese de doutorado intitulada Movimento ensino-aprendizagem no curso técnico de enfermagem: educando(a)s em contexto de vulnerabilidade social (Vieira, 2017), em que buscamos analisar o movimento ensino-aprendizagem, apreender o agir-aprendente do(a) educando(a) e o agir-educativo das educadoras, nos espaços em que os educandos e educadores vêm atuando, numa perspectiva da práxis libertadora (Freire, 2005). 
O fenômeno estudado configurou-se no processo de formação no curso técnico médio em enfermagem e nas metodologias de ensino utilizadas para o desenvolvimento da capacidade crítico-reflexiva em uma EFTS-SUS. Estudo qualitativo, descritivo e de caso único (Stake, 2007), cujo método de investigação trabalha a singularidade, significados e a intensidade do fenômeno estudado, revelando os aspectos que se tornam específicos, cujo referencial teórico-filosófico utilizado foi o de Paulo Freire.

O cenário da pesquisa foi uma EFTS-SUS do nordeste, na qual ocorreu a coleta de informações por meio de entrevistas semiestruturadas com 5 educadoras e 12 educandos(as), análise documental e observação, no período de dezembro de 2014 a setembro de 2015.

As entrevistas foram gravadas, guiadas por um roteiro semiestruturado, após analisados os critérios de inclusão, para os(as) educandos(as), de estar matriculado e frequentar regularmente o curso, e de exclusão, ausentar-se no momento da coleta, por motivos de doença ou problemas pessoais; para as educadoras, atuar há mais de seis meses na escola técnica.

A aproximação com os participantes ocorreu inicialmente pelo contato prévio da pesquisadora com a EFTS-SUS e posterior agendamento das visitas para convite aos educandos e educadoras após a assinatura do termo de consentimento livre e esclarecido. Para garantir o anonimato das participantes, as entrevistas foram identificadas pela sigla EDC para educando, seguida de número arábico de 1 a 12, e EDD para educadoras, com numeração de 1 a 5.

Os 12 educandos participantes deste estudo, em sua maioria, pertenciam ao gênero feminino, casadas e com média de 29 anos. No que se refere às cinco educadoras, todas eram do gênero feminino, casadas, enfermeiras e com idades entre 35 e 58 anos.

A observação participante foi realizada durante quatro meses, com o objetivo de apreender a categoria diálogo no movimento ensino-aprendizagem nesse curso, registrada em diário de campo construído com base nos tópicos definidos de acordo com a conceituação de Freire para diálogo e dialogicidade, na proposta de uma educação/formação humanista libertadora. Nos turnos de observação, foram acompanhadas as atividades feitas pelos educandos e educadores em sala de aula e espaços pedagógicos variados.

Os dados foram analisados qualitativamente, por meio da análise temática que possibilitou a descoberta de núcleos de sentido, levando à constituição de categorias que, na opinião de Bardin (2011), são utilizadas quando se pretende estudar ideias, opiniões, vivências, valores e atitudes. As etapas seguidas foram pré-análise, exploração do material e tratamento dos resultados: inferência e interpretação.

O referencial teórico adotado para a análise dos dados partiu da concepção de educação libertadora de Paulo Freire entendida como fenômeno 
histórico, social e coletivo, considerando os sujeitos-educadores(as) e educandos(as) como seres históricos determinados, mas também determinantes da e na realidade social em que se inserem. Ademais, o referencial da educação libertadora, pautada na problematização, é adotado pela EFTS-SUS no curso técnico referido.

As categorias de análise que emergiram das entrevistas e observação foram: diálogo na interação educador-educando no movimento ensino-aprendizagem em contexto de vulnerabilidade social; e diálogo mediando estratégias pedagógicas no movimento ensino-aprendizagem.

Por ser uma pesquisa que envolveu seres humanos, de acordo com os preceitos éticos e legais contidos na resolução n. 466/2012 do Conselho Nacional de Saúde, ela foi encaminhada ao Comitê de Ética em Pesquisa da Universidade do Estado da Bahia, recebendo parecer favorável por meio do protocolo n. 882039 e Certificado de Apresentação e Apreciação Ética (CAAE) n. 38132214.9.0000.0057.

\section{Diálogo na interação educador-educando no movimento ensino-aprendizagem}

O diálogo proporcionou a construção e o estreitamento de vínculos com os educandos, facilitando a interação no movimento ensino-aprendizagem. Abriu possibilidades para uma nova leitura de mundo dos educandos, que não é única e precede a leitura da palavra.

(...) a gente tenta saber do contexto e do cotidiano do aluno para poder chegar mais perto dele (EDD3).

(...) são adultos com história de vida muito complexas, a gente tem que aproximar a escola e os conteúdos deles (EDD5).

(...) tem que estimular o que eles já trazem de conhecimento e fortalecer o vínculo (EDDl).

O papel pedagógico das educadoras residiu na troca de saberes e interlocução, a fim de possibilitarem a si mesmas e aos educandos releituras do mundo de si próprias, no sentido de seres em ação, inacabados, incompletos e inquietos no contexto sociocultural que os constituiu e constitui (Freire, 2013b; Osowski, 2010). Esse estímulo que parte do educador, mencionado em depoimento anterior, impulsiona a curiosidade dos educandos, e esta produz inquietações, gera desvelamentos, promove novos questionamentos e a busca por seus esclarecimentos. Dessa forma, o olhar sensível do educador estimula as pessoas a se tornarem capazes de comparar, valorar, intervir, tomar decisões, romper com pensamentos cristalizados (Freire, $2011 \mathrm{~b}$ ). 
É importante a interação das educadoras com o mundo vivido pelos educandos, aproximar conhecimentos à realidade deles, como vemos nas falas das educadoras quando dizem trabalhar com temas do cotidiano dos educandos, a exemplo da violência, dificuldades na assistência e acesso à saúde. Por terem significado para eles, elas conseguem perceber a assimilação e ressignificação do conteúdo, como percebemos nas falas a seguir:

(...) quando a gente trabalha temas como violência, dificuldades na assistência, no acesso à saúde (...) então eles já trazem muitas experiências (EDD4).

(...) você consegue perceber nele essa assimilação dos assuntos, uma questão de ressignificação dos conceitos que são trabalhados (EDD3).

Essas afirmativas coincidem com o pensamento de Freire ao valorizar o processo de aprendizagem e a construção do conhecimento humano desenvolvido da interação com o ambiente no qual ele está inserido e na indissociabilidade da relação sujeito-sujeito e sujeito-mundo.

Embora o processo de construção de conhecimento compreenda uma dimensão individual na qual o educando é sujeito da sua própria aprendizagem, existe também uma dimensão social, de modo que o diálogo entre educador e educando deve sempre proporcionar a leitura do mundo e da palavra de maneira afetiva e efetiva (Freire, 2013b).

Quando as educadoras afirmam trabalhar com temas do cotidiano, como violência e dificuldades na assistência e acesso à saúde, contribuem para a reflexão crítica do conteúdo, uma vez que estão mediando discussões sobre as causas e consequências dessas e de outras situações advindas do cotidiano dos(as) educandos(as).

Dessa forma, foi imprescindível a interação pelo diálogo das educadoras com educandos no sentido de aproximação da leitura do mundo e condução ao movimento de ensino-aprendizado significativo, com base na realidade e na confiança.

\section{Diálogo mediando estratégias pedagógicas no movimento ensino-aprendizagem}

Estratégias pedagógicas são ações do professor ou do aluno que possibilitam o desenvolvimento de competências de aprendizagem predeterminadas (Vieira e Vieira, 2005), o que pode ocorrer de forma individual ou coletiva, em diversos espaços e tempos pedagógicos.

As estratégias pedagógicas utilizadas pelas educadoras foram diversas, estimulando os variados espaços, como a interação entre a sala de aula e a comunidade, tendo o diálogo como elemento mediador em todo o movimento ensino-aprendizagem norteado pelo princípio da problematização, como descrito nas falas a seguir: 
(...) proporcionamos discussão em subgrupos (EDD2).

(...) ações educativas na comunidade ou em postos de saúde (EDD1).

(...) dinâmica, rodas de conversa, seminários, apresentação de trabalhos (...) as discussões são realizadas sempre em roda ou em grupos centrado no conhecimento do aluno (EDD5).

$\mathrm{Na}$ aula expositiva dialógica, os professores tomaram como ponto de partida a experiência dos alunos relacionada com as temáticas desenvolvidas, com base na realidade vivida.

Ao contrário do que ocorre na aula expositiva tradicional, a aula expositiva dialógica valoriza a vivência dos alunos, seu conhecimento do concreto, e busca relacionar esses conhecimentos prévios com o assunto a ser estudado. O fundamento dessa nova dimensão da técnica é de que somente partindo-se do concreto é possível se chegar a uma compreensão rigorosa da realidade (Freire e Shor, 2011).

Nesse contexto, o professor é percebido como um mediador do conhecimento. A mediação ocorre pelo ato de fazer pensar, de questionar e envolvê-lo no ato reflexivo. Tal mudança na postura do professor, como intermediador e não mais transmissor do conhecimento, é percebida pelos educandos como outro fator que facilita o processo de aprendizado. O professor que medeia o conhecimento incentivando o aluno, despertando a curiosidade, valorizando as iniciativas e a solução de problemas, demonstrando nesse ato o desejo de ensinar aquilo que gosta de fazer, mantém a atitude de abertura para que o estudante participe e se envolva nesse processo. Essa capacidade de sensibilizar para a aprendizagem, por meio da relação interpessoal e da afetividade, é percebida como uma atitude positiva, principalmente por facilitar o relacionamento harmônico entre os educandos desse processo de ensino-aprendizagem (Freire, 2013a).

Para Freire (2013a), a educação problematizadora, por meio do diálogo, supera a perspectiva bancária do depósito de conteúdos e verticalização. Com isso, propõe uma educação democrática para a libertação baseada no conteúdo programático e na consciência das pessoas. Dessa forma, o estímulo ao diálogo é descrito também na organização do espaço pedagógico, proporcionando um ambiente colaborativo para a troca de experiências e ideias, como descrito pelos educandos:

(...) começa mesmo pela arrumação em sala, cadeiras em círculo, nenhuma é uma atrás da outra como aquele padrão de escola (...) um olha pro outro, um consegue ouvir melhor a fala, olhar, vê quem é que tá falando naquele momento (EDC3). 
As relações dialógicas possibilitam que as pessoas transformem o mundo e sejam transformadas por ele, somando elementos como o amor, a confiança e a criticidade, imprescindíveis para o estabelecimento de uma relação dialógica e comprometida entre as pessoas, visando à transformação por meio da reflexão e ação e da pronúncia do mundo.

As estratégias pedagógicas adotadas em sala de aula foram ao encontro da pedagogia libertadora, visto que não consideraram o educando como uma tábua rasa e depósito de conteúdos, como exposto a seguir pela educadora, ao reconhecer a importância do conhecimento prévio para o processo de formação: "eles trazem, assim, muitos conhecimentos, que a gente vai puxando, dando links pra você 'tá' trabalhando em cima do assunto" (EDD4).

No sentido dialógico-libertador, o agir-educativo do(a) educador(a) deve ser mediado pelo diálogo, segundo a leitura de mundo dos(as) educandos(as), de forma a contribuir para o desenvolvimento de um pensamento crítico sobre as situações-limites que marcam o cotidiano e a realidade dos(as) educandos(as). Na mesma direção, ser educando(a), na perspectiva dialógica, é reconhecer-se como o sujeito que é capaz de conhecer na relação com o outro sujeito (educador), igualmente capaz de conhecer. Dessa forma, o(a) educando(a) torna-se realmente educando(a) na medida em que conhece, ou vai conhecendo, os conteúdos - objetos cognoscíveis - e não na medida em que o educador deposita nele a descrição dos objetos, ou dos conteúdos (Freire, 2014b).

Pelas falas de educadoras e educandos(as), percebemos a construção e elaboração de conceitos sobre temas a serem trabalhados, valorizando conhecimentos e experiências prévias.

(...) a gente cria os conceitos das coisas tirando do que a gente sabe e a partir daí a gente cria o conceito (...) joga todo o conhecimento que a gente tem, depois cria o conceito (...) abre espaço pro aluno 'tá' debatendo (EDD3).

(...) vê primeiro o conteúdo que as pessoas têm, o conhecimento da pessoa, pra depois vir falando da teoria (...) eles não lançam pra gente, já a teoria aumenta até o poder de argumentação das pessoas de 'tá' podendo debater os assuntos e trocar experiência (EDC4).

(...) a gente é levado a expor o que a gente já conhece e já sabe, e o professor só faz complementar com o que a gente não falou, caso a gente não cite (EDC7).

Ensinar não representa a transferência de conhecimentos, nem formar refere-se à ação em que o sujeito dá forma, estilo ou alma a um corpo indeciso e acomodado. Assim, não há docência sem discência, pois as duas se explicam e se complementam, mesmo considerando as diferenças que as permeiam; não se reduzem à condição de meros objetos, pois quem ensina aprende ao 
ensinar, e quem aprende ensina ao aprender (Freire, 2011b). Esta premissa caracteriza o alicerce da educação dialógica, em que o educador valoriza os conhecimentos prévios do educando, bem como seu contexto sociocultural, e dedica-se a fomentar possibilidades de aprendizado que vão além da sala de aula. O curso ofertado aos educandos em vulnerabilidade social buscou facilitar a inserção no mundo do trabalho de pessoas que até então não possuíam alternativas para transpor suas situações-limites, demonstrando a relevância de ações como essa, que permitem retorno social.

O diálogo foi o correspondente lógico e pedagógico do pacifismo e da luta pelos direitos humanos, pela igualdade e pela aplicação universal da aprendizagem. Na obra Pedagogia do oprimido (Freire, 2013a), o diálogo foi apresentado como espaço de ação e reflexão, uma dimensão inesperada para que se ocorra a superação do senso comum. As palavras geradas pelo diálogo são transformadoras do mundo dos 'dialogantes' e do mundo que os cerca, da realidade vivida e partilhada.

Nesse contexto, para o diálogo se estabelecer é preciso que haja ação e reflexão, ou seja, práxis verdadeiras, compromisso com a palavra. Se não for assim, a palavra acaba por se tornar um ativismo, ação pela ação, ou então a reflexão se torna um emaranhado de palavras sem sentido e sem reflexão (Freire, 2013a). Dessa forma, ensinar e aprender não podem se realizar sem o exercício do diálogo, pois é impossível ensinarmos conteúdo sem saber como pensam os alunos no seu contexto real, na sua cotidianidade (Freire, 2009).

Assim, o diálogo reverberou numa 'mediação pedagógica libertadora', vinculada ao contexto social e de vida dos educandos, representada pela ação dialógica nos momentos ensino-aprendizagem, visto que a base da relação discência/docência impede de olhar qualquer um dos componentes isoladamente, além de não possuir hierarquia ou submissão (Freire e Shor, 2011).

As educadoras afirmaram, por sua vez, que o desenvolvimento das atividades em diversos espaços-pedagógicos contribui para a associação da teoria com a prática, desenvolvimento de habilidades, conhecimentos e senso crítico, devido às experiências concretas em situações reais de trabalho e de vida, e por conseguinte para a (res)significação do aprendizado pelo suporte de diversas fontes e contextos:

(...) se vai trabalhar com a criança, a gente vai pra comunidade, para o posto de saúde da unidade, então você começa a perceber a realidade deles (...) a gente passa atividades extra muros, na vivência na comunidade deles, em escolas do bairro (...) eles trazem muito a realidade locorregional deles (EDD2).

(...) eles trazem uma visão de todos os problemas que as pessoas enfrentam nessa comunidade (...) a gente também usa muito, utiliza a própria experiência do aluno, o que ele traz para a sala de aula (...) trabalha com temas que são da realidade dele, e quando você busca essa realidade fica mais claro (EDD3). 
(...) os alunos trazem exemplo do dia a dia deles, e aí a gente transforma num material conforme o tema daquela aula do módulo (EDD1).

No curso em questão, o diálogo contribuiu para o desenvolvimento de um pensamento crítico sobre as situações-limites que circundavam o cotidiano e a realidade dos educandos. Além disso, educadores e educandos reconheceram-se como sujeitos capazes de ressignificar o tempo de possibilidades e não de determinismos e, dessa forma, assumiram a luta pelo inédito viável nas condições objetivas e no contexto sócio-histórico em que vivem (Freire, $201 \mathrm{lb}$ ).

Para tanto, o diálogo se deu na busca e definição de conteúdos programáticos, em que foram implicados diferentes saberes emergidos inclusive da leitura do mundo dos educandos, respeitando a premissa da importância de desenvolver os conteúdos com base no seu contexto real, na sua cotidianidade (Freire, 2009).

Os conteúdos programáticos, juntamente com metodologias de ensino-aprendizagem inovadoras, valorizaram os cenários do cotidiano do educando e sua leitura do mundo, como hospitais, unidades básicas de saúde, palestras nas escolas da comunidade, propiciando assim a reflexão sobre temas como acesso e acessibilidade aos serviços de saúde, políticas de prevenção, promoção e reabilitação em saúde e principalmente a sua relação com o SUS (Vieira, 2017).

$\mathrm{Na}$ abordagem dos conteúdos programáticos, houve a preocupação das educadoras de fazê-la de modo que o movimento ensino-aprendizagem ocorresse voltado à realidade da clientela, considerando a necessidade de trabalhar alguns conteúdos da teoria para a prática e não da prática para a teoria, pelo fato de os(as) educandos(as) do curso não serem profissionais dos serviços de saúde. Mesmo assim, o conteúdo programático estruturado tornou-se um elemento que possibilitou a diretividade no curso, uma vez que foi fundamentado no contexto e leitura de mundo do(a) educando(a), ou seja, não partiu da sua experiência como profissional, mas da sua vivência no contexto a que pertence, a exemplo de situações de violência associadas a causas externas e populações vulneráveis.

Verificamos a introdução das experiências e vivências ao conteúdo e ensino, de modo que o(a) educando(a) se sentisse desafiado(a) a buscar novos conhecimentos e estratégias, desenvolvendo-se com criatividade e criticidade, na compreensão da realidade e suas possibilidades de transformação, incorporando questões técnicas da enfermagem e questões de políticas de saúde, tomando por base a contextualização com o SUS (Siqueira e Leopardi, 2016).

Assim, a articulação da teoria com a prática, juntamente com as dimensões biopsicossociais e tomando a realidade como motivadora da aprendizagem significativa, buscou construir um processo educativo alicerçado nos saberes prévios dos(as) educandos(as), tendo por objetivo tornar o processo educativo mais dinâmico. Houve uma necessidade contínua de transformar a 
prática pedagógica em momento de prazer e satisfação tanto para o educador como para o educando, a fim de tornar o processo educativo mais humanizado e motivador.

Nesse sentido, o(a) educando(a) construiu o seu pensar crítico-reflexivo durante as imersões nos diferentes cenários, relacionando a prática à teoria obtida nas buscas por meio do diálogo, na resolução de problemas, procurando a autonomia, tornando os processos essenciais para a construção do conhecimento articulado com a realidade, de forma crítico-reflexiva, efetiva para a integração entre ensino e prática profissional.

Entendemos pelas falas dos(as) educandos(as) que o processo de conscientização está em andamento, pois ainda possui características de aspectos individuais e ingênuos, sobrepondo-se à visão coletiva, crítica e politizada. Entretanto, consideramos esse processo de conscientização importante e relevante, ao apreendermos que eles estão se situando e se comprometendo em seu contexto histórico social e cultural, o que revelou a necessidade de exercitar a consciência em seus diversos estágios para alcançar a consciência de si no mundo, na concepção de ser de potencialidade, em busca da conscientização.

Na perspectiva do diálogo e educação problematizadora-libertadora, consideramos as diferentes formas de expressão dos educandos valorizando as suas falas, mediatizados por metodologias participativas como a arte, a música e a educação em saúde no contexto social de vulnerabilidade e dos sonhos possíveis deles.

Dessa maneira, foi incentivada a prática educativa política, no espaço-tempo pedagógico e da experiência gnosiológica que é a referente ao que permeia o processo de produção do conhecimento em si, pois não há prática educativa que não esteja envolvida em sonhos, que não envolva valores, projetos e utopias. Não há prática educativa sem ética e diálogo (Freire, 2013b).

Os educadores respeitaram a identidade cultural dos educandos abordando conteúdos técnicos e associando-os de modo que tivessem significância para sua vida profissional. Requereu-se, portanto, habilidade do educador para estimular a criatividade principalmente pela criação de estruturas pedagógicas que promoveram o exercício da autonomia dos educandos, como as ações de intervenção na própria comunidade.

O diálogo entre educador e educando nesse curso pautou-se numa formação que estimulou a reflexão, a decisão, o compromisso e o engajamento numa causa comprometida com a transformação da realidade, que atribuísse sentido à existência e com o SUS se fazendo presente na definição de alguns conteúdos programáticos, refletindo os anseios e esperanças (Freire, A., 2001), e não se traduzindo somente em um conjunto de informações a ser depositado nos(as) educandos(as) em programas organizados por gestores(as) ou professores(as).

Portanto, o diálogo contribuiu para o movimento ensino-aprendizagem, pois possibilitou, entre outros benefícios, que os educandos decodificassem 
as informações recebidas com base em estímulos vivenciais, transformando-as em conhecimento, aprendizagem, no seu tempo de aprender. Propiciou a retomada da individualidade na arte de conhecer, sem, no entanto, excluir a influência do grupo social na construção desse mesmo saber.

Esse modo de ensino-aprendizagem com o movimento dialógico demonstrou uma ação-proposta pedagógica contra-hegemônica, ao romper, em alguns momentos, com a organização e execução de conteúdos e práticas docentes desarticuladas da vida cotidiana. Foi, portanto, na direção de uma educação emancipatória, em prol da autonomia que requer uma formação cada vez mais significativa e consciente, durante toda a vida dos indivíduos, reafirmando a importância da consistência do trabalho educativo em uma perspectiva democrática, conjunta e genuinamente compromissada (Freire, 2011a).

Nesse sentido, acreditamos que a formação dos profissionais de saúde deve ser considerada como um projeto educativo que transcenda a educação visando ao domínio técnico-científico da profissão. Deve, portanto, incluir aspectos estruturantes de relações e práticas em todos os componentes de interesse ou relevância social que contribuam para a elevação da qualidade de saúde da população, no enfrentamento tanto dos aspectos epidemiológicos do processo saúde-doença quanto daqueles de organização da gestão setorial e estruturação do cuidado à saúde (Ceccim e Feuerwerker, 2004).

Tendo a educação como meio e interface, e não como finalidade, poderá ser possível a emancipação do sujeito, lutando contra discursos hegemônicos e armadilhas ideológicas - os quais, por vezes, conferem equivocadamente um caráter neutro à educação, anestesiando ou tornando míopes sujeitos-objetos da formação profissional.

\section{Educação profissional em saúde em enfermagem: diálogo com o pensamento freireano}

A educação profissional em saúde foi legalmente constituída pela lei n. 4.024, de 1961, influenciada pelo contexto nacional decorrente da necessidade de programas de saúde e melhoria da organização sanitária, dando sustentação à noção dos recursos humanos em saúde, o que se repetiu ao final dos anos 1980, com a chamada expansão e democratização da educação profissional no Brasil, em razão das expectativas de elaboração de uma nova política pública para o setor, no âmbito de um projeto nacional de desenvolvimento (Campello e Lima Filho, 2009).

Com relação à educação profissional técnica de nível médio em enfermagem, os marcos legais foram a regulamentação do curso em 1966 e o reconhecimento em 1986, com a lei n. 7.498, regulamentada pelo decreto n. 94.406, de 1987, que dispôs sobre o exercício profissional da enfermagem (Oguisso, 1997; Santos, 2005). 
Historicamente, a educação profissional é vista como subeducação, reservada às classes menos favorecidas, destinando-se a desvalidos da sorte, assumindo um caráter assistencialista e servil, que tem marcado todo o seu legado (Santos, 2005) - o que nos leva a analisar o desvirtuamento do conceito de educação, pois “a educação deve preparar ao mesmo tempo para um juízo crítico das alternativas propostas pelas elites, e dar a possibilidade de escolher o seu próprio caminho" (Freire, 2016, p. 20).

Para tanto, é necessário lutar pela 'liberdade', que só é alcançada quando os(as) educadores(as) assumem o compromisso de fazer emergir o potencial humano de cada educando(a), transformando a educação num instrumento de libertação humana e não de domesticação (Freire, 2013a, 2013b).

Desse modo, corroboramos as ideias de Freire (2013b) ao afirmar que não há prática educativa que não seja política, sem sujeitos-educador e educando, fora do espaço-tempo pedagógico e da experiência gnosiológica que é a experiência do processo de produção de conhecimento em si. Não há prática educativa que não esteja envolvida em sonhos, que não envolva valores, projetos, utopias. Não há prática educativa sem ética.

Faz-se necessário, então, a leitura do mundo e o movimento dialógico educador(a)- educando(a), de modo a mediatizar o conhecimento vivido e não reproduzir o enfoque tecnicista associado aos profissionais técnicos de enfermagem.

Importante ressaltar que Paulo Freire não considerava a prática educacional como único caminho para a transformação social necessária à conquista dos direitos humanos. Contudo, para ele, sem ela jamais haveria a transformação social, pois a educação propicia às pessoas maior clareza para 'lerem o mundo', sendo este atributo que abre possibilidades de intervenção política sempre difícil, porém possível e urgente (Freire, 2014a, 2014b).

Tendo a educação como meio e interface, e não como finalidade, poderá ser possível a emancipação do sujeito, lutando contra discursos hegemônicos e armadilhas ideológicas, os quais, por vezes, conferem equivocadamente um caráter neutro à educação, anestesiando ou tornando míopes os sujeitos-objeto da formação profissional.

As transformações desejadas no modelo de atenção à saúde requerem a formação de profissionais com capacidade crítico-reflexiva e criativa. Para alcançarmos isso, a formação de enfermeiras precisa reconhecer o processo de ensinar e aprender como uma construção de saberes para a efetiva integração entre ensino e prática profissional.

\section{Reflexões da educação profissional no contexto de vulnerabilidade social}

A vulnerabilidade, numa definição lata, é o potencial para a perda, constituída por elementos de exposição ao risco e de propensão a eles (Cutter, 1996), produto de determinados contextos espaciais, socioeconômicos, demográficos, 
culturais e institucionais, pelo que a sua abordagem é sensível às condições locais e à dimensão temporal.

O termo vulnerabilidade pode ser de um indivíduo, família ou grupos sociais e refere-se à maior ou à menor capacidade de controlar as forças que afetam seu bem-estar (Brasil, 2006), e as populações vulneráveis são aquelas que se encontram em risco, não simplesmente porque estão expostas aos perigos, mas como resultado da marginalidade em que vivem, fazendo das suas vidas uma emergência permanente (Cutter, 1996).

A vulnerabilidade social é conceito polissêmico e multifacetado, composto por diversos indicadores, compreendida por Ayres, França Júnior e Calazans (2003) como a falta do sujeito aos recursos como informação, recursos materiais e cognitivos, revelando-se como questões de renda e pobreza, estigmas sociais e discriminação, condições de moradia, mas não se reduzindo à pobreza e renda. Pode ser considerada como multifatorial e transitória, não sendo traduzida como uma condição fatalista e determinante aos seres humanos, o que pode levar ao desafio da transformação de situações-limites na busca do ser-mais (Freire, 2000).

Ainda sobre a vulnerabilidade social, ela está associada com a identificação de fatores e indicadores multidimensionais de exclusão e inclusão social, necessitando, dessa forma, de uma abordagem ampla e intersetorial. É uma situação em que o conjunto de características, recursos e habilidades que diz respeito a um determinado grupo social se revela insuficiente, inadequado ou com pouquíssima oportunidade de concretização e ascensão social, devido à falta de acesso a bens e serviços oferecidos pela sociedade e pelo Estado, não sendo apenas do sujeito, mas também do contexto no qual está inserido (Vignoli, 2001).

Mesmo compreendendo os danos físicos, psicológicos e morais que a vulnerabilidade social pode causar ao ser humano, concordamos com Ramos (2010), ao refletir com base em conceitos freireanos, que

embora todos os seres humanos nasçam condicionados por fatores materiais, econômicos, sociais, políticos, culturais e ideológicos, dotando-os de identidade e inserindo-os em um contexto com características próprias que são, indiscutivelmente, preponderantes em suas formações, tais condicionantes não se constituem como obstáculos insuperáveis. São passíveis de transformação pela ação humana, dado justamente o caráter histórico do homem (Ramos, 2010, p. 220).

A amplitude multidimensional da exclusão/inclusão social gerada pela vulnerabilidade social necessita de uma abordagem multifatorial e contextualizada, visto que para a transformação social é necessária uma dinâmica criativa e contínua de intervenção social, na medida em que não existe um padrão de resposta e nem sempre uma intervenção aplicada a uma questão social de determinado lugar servirá para outro. Para tanto, é importante prestar aten- 
ção às diferentes formas de exclusão social para, posteriormente, seguir com a aplicação de políticas públicas com maior nível de sucesso e continuidade.

Nesse aspecto, faz-se necessário que as estratégias de inclusão social sejam elaboradas de acordo com a demanda dos interessados e necessitados, de modo a não se caracterizarem como programas assistencialistas não sustentáveis, tal qual ocorreu com o curso apresentado.

Desse modo, pode-se caracterizar tal iniciativa como uma estratégia que possibilitaria a inclusão social, sendo necessário, para tanto, ações que reforcem ou ajudem a elaborar políticas públicas sustentáveis, não assistencialistas, compreendendo os jovens-adultos como sujeitos de direitos e atores em seu processo de desenvolvimento pessoal e profissional.

Assim, mesmo com o conhecimento de que são várias as medidas para a minimização dos fatores que contribuem para o incremento ou reduzir danos em comunidade em contexto de vulnerabilidade social, tomamos como referência a educação profissional em enfermagem, acreditando que a transformação da sociedade é realizada por mulheres e homens motivados pelo sonho possível e inédito viável, mediado pelo diálogo.

Ao se considerar o perfil ingresso e egresso nesse curso, ratificam-se os determinantes de pessoas menos favorecidas economicamente e socialmente, muitas vezes encontradas em situação de vulnerabilidades individuais, coletivas e sociais.

A educação profissional, nesse contexto, materializa a esperança revestida na possibilidade de emprego, reconhecimento social e inclusão, à medida que ocorre a mobilização/movimento pelo estudo e escolarização, pois não há esperança na imobilidade e na paralisia (Freire, 2014b).

O diálogo, nesse movimento, alimenta a busca de lutas e, baseado na ação, impede tanto a acomodação pragmática à realidade quanto a fuga para idealismos, conjuntamente com a esperança advinda com a educação profissional, o que impulsiona e movimenta comunidades em vulnerabilidade social, possibilitando ir além das situações-limites, essas que não devem ser tomadas como se fossem barreiras insuperáveis, geradoras de desesperança (Freire, 2000, 2014b).

Segundo Paulo Freire,

a educação tem sentido porque o mundo não é necessariamente isto ou aquilo, porque os seres humanos são tão projetos quanto podem ter projetos para o mundo. A educação tem sentido porque mulheres e homens aprendem que é aprendendo que se fazem e se refazem, porque mulheres e homens se puderam assumir como seres capazes de saber, de saber que sabem, de saber o que ainda não sabem. De saber melhor o que já sabem, de saber o que ainda não sabem. A educação tem sentido porque, para serem mulheres e homens, precisam estar-sendo. Se mulheres e homens simplesmente fossem, não haveria por que falar em educação (Freire, 2000, p. 40). 
Nesse contexto, a educação por meio da formação para a profissão pode contribuir para a busca do ser-mais, transpondo os muros burocráticos dos projetos, para poder de fato influenciar na vida das pessoas.

Percebemos que estamos no caminho certo para a formação de um profissional crítico-reflexivo e criativo, sabendo que o que importa não é a repetição mecânica do gesto, mas a compreensão da importância da sua ação (responsável e comprometida com seu contexto), a tomada da consciência da realidade, decifrando sua maneira de ser, pensar e agir, bem como deixando claro que alguns saberes são necessários à prática docente libertadora e transformadora. E que ensinar não é simplesmente transmitir conhecimento.

\section{Perspectivas da educação profissional embasada no referencial freireano}

A educação problematizadora se propõe a mobilizar a construção de conhecimentos com base em experiências significativas. Na aprendizagem significativa, busca-se construir um processo educativo alicerçado nos saberes prévios dos educandos, tendo por objetivo tornar o processo educativo mais dinâmico. Existe uma necessidade contínua de transformar a prática pedagógica em momento de prazer e satisfação tanto para o educador como para o educando, a fim de tornar o processo educativo mais eficaz (Freire, 1969; Bahia, 2007, 2009).

Neste estudo, os(as) educandos(as) perceberam o educador como mediador da reflexão e facilitador do processo de aprendizagem. Para isso, deve-se ter conhecimento do que se vai ensinar e, pela habilidade didático-pedagógica, articular e ampliar o conteúdo programático com a realidade, pois não há receitas prontas no processo ensino-aprendizagem. Existem metodologias que precisam ser conhecidas, bem abordadas e adequadas a diferentes situações e indivíduos. Isso só acontece quando o educador orienta sua prática pedagógica em uma perspectiva problematizadora, assumindo o papel de agente de transformação pela sua capacidade de ligar e religar os saberes. Para tanto, as práticas pedagógicas devem nortear os educadores para atingir os objetivos da educação problematizadora, fazendo com que o educando seja um protagonista de seu processo de aprendizagem e os educadores assumam o papel de mediadores/facilitadores.

Para que ocorra essa transformação no processo ensino-aprendizagem, a formação do educador enfermeiro deve ser crítica e reflexiva, para que ele possa transpor as barreiras da educação tradicional. Porém, o trabalho docente é considerado empirista, uma vez que, na ausência de formação pedagógica, as experiências prévias constituem-se em guias para a projeção das necessidades do discente.

Assim, na perspectiva freireana, o conhecimento produzido nesse movimento mediado pelo diálogo não possui hierarquia ou submissão, já que somos seres programados para ensinar e aprender. Ensino e aprendizagem são ações 
que envolvem educadores(as) e educandos(as), em que o que ensina aprende, de um lado, porque reconhece um conhecimento antes aprendido, e de outro, porque observa a maneira como a curiosidade do discente aprendiz trabalha.

Por isso, a educação problematizadora fundamenta-se na relação dialógica entre educador e educando, que possibilita a ambos aprenderem juntos, por meio de um processo emancipatório. Assim, as instituições de ensino devem despertar nos educadores e educandos a compreensão da educação como uma nova forma, dialógica e libertadora, que supere os limites da educação tradicional e tecnicista. A importância do papel do professor como agente de mudança, favorecendo a compreensão mútua e a tolerância, nunca foi tão patente como hoje em dia (Freire, 2009).

Assim, definimos que na educação problematizadora o ensino não pode ser uma prática de depósito de conteúdos apoiada numa concepção de homens como seres vazios, mas deve elaborar e reelaborar conhecimentos, estimulando a curiosidade dos educandos, propor desafios, problemas e incentivar a busca de soluções das ações desenvolvidas.

Certamente, esse modo de promover educação, nos espaços de educação formal, indica caminhos possíveis, mas que não são fáceis e necessitam ser construídos na coletividade, num movimento em que o agir provoca a mudança crítica. Esse é o fundamento da educação libertadora anunciada por Freire (2005), que se realiza por meio dos diálogos, inerentes à metodologia empreendida, num processo em que pesquisador(a) e pesquisados(as) desafiam-se mutuamente, no sentido de encontrar e recriar lugares de encontro, potencializando o saber científico e o saber popular.

O material utilizado evidenciou-se como um importante instrumento de pesquisa ao aproximar educadora e educandos. É importante nos referirmos à riqueza do material empírico sobre as denúncias e sobre os anúncios encontrados nos registros dos formulários de pesquisa dos educadores e dos educandos. Por isso, hoje se faz necessário que educadores e educandos superem o modelo do ensino tradicional, desvencilhando-se do velho para construir o novo. E nesse processo, a primeira atitude é aceitar o novo, para em seguida reinventar suas atitudes sobre a realidade, estando aberto para as incertezas, reorganizando seu pensamento e sua ação (Freire, 2011b).

Nesse sentido, o modelo tradicional de ensino na saúde, para ser superado, requer que os docentes reconheçam a importância da formação pedagógica como um conhecimento necessário a uma prática pedagógica competente, rompendo com a prática educativa amadora. Portanto, o profissional da saúde, que em sua maioria não tem formação para a área da educação, deve atualizar-se constantemente e desenvolver a curiosidade intrínseca ao educador.

Paulo Freire, em seu livro Pedagogia da autonomia faz a afirmação que “[...] sem a curiosidade que me move, me inquieta, me insere na busca, não 
aprendo nem ensino" (Freire, 2011b, p.33) e, concordando com o autor, educar é um ato de amor, de respeito que exige pesquisa, rigorosidade, estética e ética.

$\mathrm{Na}$ experiência da pesquisa, a aprendizagem do diálogo evidenciou, à educadora e aos educandos, que as aprendizagens se fazem e se refazem na cotidianidade da ação, dia após dia.

Na dialética de ensinar e aprender, o diálogo constituiu-se como possibilidade de abrir caminhos para o movimento ensino-aprendizagem. A confiança na relação da educadora com o educando incentivou ambos à tomada de consciência na condição de ser capaz de aprender e buscar novas aprendizagens.

O educador, como mediador do conhecimento, criou condições para a construção de novas aprendizagens mediadas pelo diálogo crítico, amoroso e ético por meio da confiança. Desse modo, compreendeu que a práxis dialógica exercida com as aprendizagens mediatizadas pelo diálogo e confiança potencializou a mudança de visão de si como sujeito aprendiz.

Enfim, no percurso da experiência dos diálogos, como base do processo de ensino- aprendizagem com educandos(as), bem como com os(as) educadores(as), ampliou-se a compreensão de que se aprende a ser educador sendo.

\section{Algumas considerações do diálogo no movimento de ensino-aprendizagem}

Alguns aspectos da vulnerabilidade social dos(as) educandos(as) foram considerados no movimento do curso, evidenciando a necessidade de adequações de sua metodologia às características sociais, econômicas e de vida dos(as) educandos(as).

O diálogo proporcionou a construção e o estreitamento de vínculos, contextualizar o conteúdo teórico com referência no território e na leitura de mundo dos(as) educandos(as), bem como mediou estratégias pedagógicas que fortaleceram o conhecimento dialógico e plural.

O diálogo verdadeiro, simétrico, solidário e cooperativo, defendido e praticado por Freire, revelou-se um importante mediador no movimento ensino-aprendizagem no curso técnico em enfermagem promovido por uma EFTS-SUS para educandos(as) em contexto de vulnerabilidade social.

Este estudo mostrou que as educadoras não assumiram o papel de depositárias de uma formação tecnicista e cartesiana com relação aos educandos, assim como os educandos perceberam o seu processo de formação como dialógico e participativo, destacando as metodologias problematizadoras como importantes estratégias para o movimento ensino-aprendizagem. Verificamos elementos importantes que foram ao encontro do ensino-aprendizagem problematizador, com a valorização de aprendizagens significativas e diálogo mediado pela diretividade e afeto, apesar de considerar os limites da formação das enfermeiras no âmbito didático-pedagógico, o que acreditamos ser decorrente de deficiências que as acompanham desde a graduação até o mundo do trabalho. 
Portanto, o movimento ensino-aprendizagem pautado no diálogo resultou em educadoras e educandos implicados na construção conjunta de saberes, configurando-se, em sua concepção dialética, como elemento humanizador e transformador da realidade, em coerência com o conceito genuinamente freireano, que pressupõe transcender dicotomias e compreender o homem como entidade responsável, crítica e problematizadora, capaz de promover esse processo entre pessoas em desenvolvimento, ativamente implicadas na construção de seus processos sociais, históricos, culturais e políticos.

Apreendemos que o diálogo, no contexto apresentado, teve um propósito marcado socialmente, pois atuou em prol da transformação dos(as) educandos(as) e da construção do seu processo de conscientização, à medida que estimulou a participação na discussão dos conteúdos programáticos com base em suas vivências e leitura de mundo, bem como na condução ativa nos momentos de aprendizagem, representada pela diversificação dos cenários e espaço-tempo pedagógicos.

A educação, na condição de instrumento de transformação social, aproximou distintas realidades e promoveu o reconhecimento dos limites, das potencialidades e do ser-mais que conduz a luta contra toda visão de imobilismo, determinação do futuro, fatalismo e aniquilamento de sonhos, vinculados perversamente a educandos(as) em contexto de vulnerabilidade social.

Tratou-se da busca constante de reaprender a ser com o outro, compreendendo, na teoria e na prática, o sentido do 'ser mais' por meio da experiência do diálogo. Compreende-se, portanto, que criar um ambiente de diálogo e de confiança é responsabilidade do educador, juntamente com os educandos, e que a organização de diálogos pode contribuir para aproximar educadores e educandos.

Recomendamos considerar e refletir sobre que as políticas educacionais não dão conta, sozinhas, dos desafios enfrentados pelo sistema educacional brasileiro, em especial, no ensino médio, no qual se situa a educação profissional.

Políticas educacionais e de trabalho necessitam estar articuladas com as políticas de redução das desigualdades sociais, econômicas e com as políticas de saúde, segurança, cultura e lazer. Sem isso, será difícil garantir oportunidades concretas de futuro, inserção qualificada e competente no mundo do trabalho e participação cidadã na vida em sociedade.

Para tanto, ao lado da necessária articulação entre as políticas educacionais e outras da esfera social, faz-se necessário que o movimento ensino-aprendizagem na educação profissional técnica de nível médio em enfermagem tenha como princípios a formação de profissionais éticos, críticos, reflexivos e comprometidos com o sistema de saúde e seus usuários, como recomendado nas diretrizes curriculares nacionais para a educação profissional de nível técnico e nas diretrizes curriculares nacionais do curso de graduação em enfermagem. 
Este estudo pretendeu contribuir para a reflexão de educadoras, educandos e gestores envolvidos na formação técnica de nível médio em enfermagem, quer seja de EFTS-SUS, quer de instituições privadas ou públicas, no que tange a repensar os princípios da formação de adultos vinculados à educação libertadora, crítica e refletiva, para construir uma formação integrada em detrimento da dicotomia entre o pensar e o fazer, ainda existente na formação técnica da saúde e em enfermagem, colaborar para a formação humana e técnica.

Acreditamos que os resultados desta pesquisa poderão subsidiar a gestão da escola técnica do SUS e nos âmbitos das secretarias de saúde e de segurança pública, fornecendo elementos do movimento ensino-aprendizado na formação de técnicos em enfermagem.

Possibilita, portanto, que outras iniciativas intersetoriais sejam desenvolvidas e que possam contribuir para a formação humana e técnica de pessoas em situação de vulnerabilidade social, ampliando dessa forma o escopo de formação das EFTS-SUS, aproveitando a capilaridade delas em todo o território nacional.

Em síntese, este estudo resultou da experiência da compreensão acerca do potencial formativo do pensamento freireano para orientar a reflexão sobre a prática dialógica, tendo em vista constituir processos educativos emancipatórios, tanto para os educandos quanto para as educadoras. Ampliar essa compreensão é uma perspectiva que se anuncia e desafia a continuidade da experiência da pesquisa e do ensino em diferentes espaços.

\section{Colaboradores}

Silvana Lima Vieira foi responsável pela coleta de dados, redação, revisão e formatação do artigo. Gilberto Tadeu Reis da Silva, Rosana Maria de Oliveira Silva e Simone Coelho Amestoy contribuíram com a redação, revisão e formatação do artigo.

\section{Financiamento}

Este suplemento “Educação e Trabalho em Saúde: diálogos e experiências no Brasil e em Portugal" foi realizado com apoio da Coordenação de Aperfeiçoamento de Pessoal de Nível Superior (Capes) - Código de Financiamento 001; e do Departamento de Pesquisa em História das Ciências e da Saúde da Casa de Oswaldo Cruz (Depes/COC/Fiocruz, 6151000000). Todos os autores declaram que não há conflito de interesses. 


\section{DIÁLOGO Y ENSEÑANZA-APRENDIZAJE EN LA FORMACIÓN TÉCNICA EN SALUD}

Resumen Este artículo ha tenido como objetivo analizar el actuar-aprendiz del educando y el actuar-educativo de las educadoras en el movimiento enseñanza-aprendizaje considerando sus contribuciones para el campo de la formación en un Curso Técnico de Nivel Secundario en Enfermería, impulsado por la Escuela de Formación Técnica en Salud del Sistema Único de Salud de Brasil. Estudio cualitativo, del tipo estudio de caso, anclado en el referencial de Paulo Freire. Han participado de este estudio 12 educandos y cinco educadoras, con los datos recogidos entre diciembre de 2014 y septiembre de 2015 por medio de entrevista semiestructurada, observaciones registradas en diario de campo y análisis documental. El dialogo en uso de metodologías innovadoras y problematizadoras ha proporcionado la construcción y estrechamiento de vínculos, contextualización del contenido teórico con base en el territorio y en la lectura de mundo de los educandos en la búsqueda de una relación dialógica. El potencial formativo del pensamiento freireano ha guiado la reflexión e práctica fundamentada en diálogo, que ha contribuido para el proceso educativo emancipatorio y plural. Concluimos que el diálogo proporcionó una estrecha relación entre educadores y educandos, revelándose como idea/fuerza, favoreciendo la dinámica sensible y critica que permeó y constituyó el movimiento enseñanza-aprendizaje para educandos en contexto de vulnerabilidad social.

Palabras clave movimiento enseñanza-aprendizaje; formación profesional; enfermería; diálogo; vulnerabilidad social. 


\section{Referências}

AYRES, José R.; FRANÇA JÚNIOR, Ivan; CALAZANS, Gabriela J. et al. O conceito de vulnerabilidade e as práticas de saúde: novas perspectivas e desafios. In: CZERESNIA, Dina;

FREITAS, Carlos M. (orgs.). Promoção da saúde: conceitos, reflexões, tendências. Rio de Janeiro: Editora Fiocruz, 2003. p. 117-140.

BAHIA. Secretaria de Saúde. Superintendência de Recursos Humanos da Saúde. Avaliando competências: construção de indicadores e critérios (relatório final). Salvador: Escola de Formação Técnica em Saúde Professor Jorge Novis, 2004.

BAHIA. Secretaria de Saúde. Superintendência de Recursos Humanos da Saúde. Projeto Político Pedagógico (PPP): Escola de Formação Técnica em Saúde Professor Jorge Novis. Salvador: SUPERH/EFTS, 2007.

BAHIA. Secretaria de Saúde. Superintendência de Recursos Humanos da Saúde. Plano de curso: habilitação profissional de técnico em enfermagem - Escola de Formação Técnica em Saúde Professor Jorge Novis. Salvador: SUPERH/EFT, 2009.

BAHIA. Secretaria da Segurança Pública. Planesp: Plano Estratégico do Sistema Estadual da Segurança Pública - Salvador: EGBA, 2017 136 p.; il. Disponível em: <http://www.ssp. ba.gov.br/arquivos/File/Projetos/PLANESP. pdf $>$ Acesso em: 06/09/2019.

BARDIN, Laurence. Análise de conteúdo. São Paulo: Edições 70, 2011.

BRASIL. Ministério da Saúde. Secretaria Executiva. Departamento de Apoio à Descentralização. Regulamento dos pactos pela vida e de gestão. Brasília: Ministério da Saúde, 2006. (Série A. Normas e Manuais Técnicos).

BRASIL. Ministério da Educação. Lei n. 13.005, de 25 de junho de 2014. Plano Nacional de Educação e dá outras providências. Diário Oficial da União, Brasília, 05 set. 2019. http://www. planalto.gov.br/ccivil_03/_ato2011-2014/2014/ lei/113005.htm

CAMPELLO, Ana M.; LIMA FILHO, Domingos L. Educação profissional. In: PEREIRA, Isabel B.; LIMA, Júlio C. F. In: Dicionário da educação profissional em saúde. 2. ed. Rio de Janeiro: EPSJV, 2009. p. 175-182.

CECCIM, Ricardo B.; FEUERWERKER, Laura Mudança na graduação das profissões de saúde sob o eixo da integralidade. Cadernos de Saúde Pública, Rio de Janeiro, v. 20, n. 5, p. $1.400-$ 1.410, set.-out. 2004.

CUTTER, Susan. Vulnerability to environmental hazards. Progress in Human Geography Columbia, v. 20, n. 4, p. 529-539, 1996.

DEWEY, John. Como pensamos: como se relaciona o pensamento reflexivo com o processo educativo; uma reexposição. 3. ed. São Paulo: Nacional, 1959.

DEWEY, John. Experiência e educação. São Paulo: Nacional, 1971.

FREIRE, Ana M. A. Paulo Freire: sua vida, sua obra. Educação em Revista, Marília, v. 2, n. 1, p. 1-13, 2001.

FREIRE, Paulo. Papel da educação na humanização. Revista Paz e Terra, São Paulo, n. 9, p. 123-132, out. 1969.

FREIRE, Paulo. Pedagogia da indignação: cartas pedagógicas e outros escritos. São Paulo: Editora da Unesp, 2000.

FREIRE, Paulo. Sobre educação: diálogos (Paulo Freire e Sérgio Guimarães). 5. ed. Rio de Janeiro: Paz e Terra, 2001.

FREIRE, Paulo. A educação na cidade. 6. ed. São Paulo: Cortez, 2005.

FREIRE, Paulo. Professora sim, tia não: cartas a quem ousa ensinar. São Paulo: Olho d'Água, 2009. 
FREIRE, Paulo. Educação e mudança. 2. ed. São Paulo: Paz e Terra, 201 la.

FREIRE, Paulo. Pedagogia da autonomia: saberes necessários à prática educativa. 43. ed. São Paulo: Paz e Terra, 2011 b.

FREIRE, Paulo. Pedagogia do oprimido. 54. ed. Rio de Janeiro: Paz e Terra, 2013a.

FREIRE, Paulo. Educação como prática da liberdade. 15. ed. São Paulo: Paz e Terra, 2013b.

FREIRE, Paulo. Pedagogia dos sonhos possíveis. São Paulo: Paz e Terra, 2014a.

FREIRE, Paulo. Pedagogia da esperança: o encontro com a pedagogia do oprimido. 54. ed. Rio de Janeiro: Paz e Terra, 2014b.

FREIRE, Paulo. Conscientização. São Paulo: Cortez \& Moraes, 2016.

FREIRE, Paulo; SHOR, Ira. Medo e ousadia: o cotidiano do professor. 13. ed. Rio de Janeiro: Paz e Terra, 2011.

OGUISSO, Taka. Considerações sobre a legislação do ensino e do exercício do técnico de enfermagem e do auxiliar de enfermagem. Revista Brasileira de Enfermagem, Rio de Janeiro, v. 30, n,2, p. 168-174, 1997.

OSOWSKI, Cecília I. Situações-limites (verbete). In: STRECK, Danilo; REDIN, Euclides; ZITKOSKI, Jaime J. (orgs.). Dicionário Paulo Freire. Belo Horizonte: Editora Autêntica, 2010. p. 375-376.

RAMOS, Marise N. Trabalho, educação e correntes pedagógicas no Brasil: um estudo a partir da formação dos trabalhadores técnicos da saúde. Rio de Janeiro: EPSJV, 2010.

SANTOS, Lucia H. Estratégias e avaliação no processo ensino aprendizagem e a postura do professor na educação profissional em enfer- magem. 149 f. Tese (Doutorado em Ciências da Saúde) - Faculdade de Enfermagem, Universidade de São Paulo, Ribeirão Preto, 2005.

SIQUEIRA, Márcia C. G.; LEOPARDI, Maria T. O processo ensino-aprendizagem na formação de trabalhadores do SUS: reflexões a partir da experiência da ET-SUS. Trabalho, Educação e Saúde, Rio de Janeiro, v. 14, n. 1, p. 119-136, jan.-abr. 2016.

STAKE, Robert. A arte da investigação com estudos de caso. Tradução Ana Maria Chaves. Lisboa: Fundação Calouste Gulbenkian, 2007. $187 \mathrm{p}$.

VIEIRA, Rui M.; VIEIRA, Celina. Estratégias de ensino/aprendizagem: questionamento promotor do pensamento crítico. Lisboa: Instituto Piaget, 2005.

VIEIRA, Silvana L. Movimento ensino-aprendizagem no curso técnico de enfermagem: educando(a)s em contexto de vulnerabilidade social. 2017. 146 f. Tese (Doutorado em Enfermagem) - Escola de Enfermagem, Universidade Federal da Bahia, Salvador, 2017.

VIGNOLI, Jorge R. Vulnerabilidade demográfica en América Latina: qué hay de nuevo? Santiago: Cepal, 2001.

WESTBROOK, Robert; TEIXEIRA, Anísio. John Dewey. Recife: Massangana, 2010. Disponível em: <http://www.dominiopublico. gov.br/download/texto/me4677.pdf $>$. Acesso em: $1^{\circ}$ dez. 2015.

ZITKOSKI, Jaime J. Diálogo/Dialogicidade (verbete). In: STRECK, Danilo; REDIN, Euclides; ZITKOSKI, Jaime (orgs.). Dicionário Paulo Freire. Belo Horizonte: Autêntica Editora, 2010; p. 117-118. 